\title{
Effect of thermal processing and storage condition on the flavour stability of spray- dried durian powder.
}

\begin{abstract}
Stability of key odour volatiles (propanethiol, ethyl propanoate, ethyl 2-methylbutanoate and diethyl disulfide) from spray-dried durian powder that was subjected to accelerated storage were analysed quantitatively using headspace solid phase microextraction coupled to fast gas chromatography-mass spectrometry. The type of drying aids incorporated significantly influenced volatiles retention in the powder product. The addition of gum Arabic resulted in higher retention of volatiles in the durian powder as compared to maltodextrin and N-Lok starches. Volatiles that remained in the powder ranged from $57 \%$ to $76 \%$ of the original concentration. Volatile composition of the powder product was altered with only two aldehydes included 2- and 3-methyl butanal and no off-flavour volatile was detected throughout the storage. The rates of volatiles release from the spray-dried powder under accelerated storage condition increased markedly at higher relative humidity.
\end{abstract}

Keyword: Durian; Spray drying; Volatiles retention; Accelerated storage; Drying aids. 